\title{
Evaluation of removal efficiency of phenol from synthetic aqueous solutions by Citrullus colocynthis seed ash
}

\author{
Samira Salari ${ }^{1}$, Mojtaba Afsharnia $^{1}$, Asiyeh Moteallemi ${ }^{2 *}$, Mehdi Ghasemi ${ }^{1}$ \\ ${ }^{1}$ Department of Environmental Health Engineering, School of Health, Gonabad University of Medical Sciences, Gonabad, Iran \\ ${ }^{2}$ Department of Environmental Health Engineering, School of Nursing, Torbat Jam Faculty of Medical Sciences, Torbat Jam, Iran
}

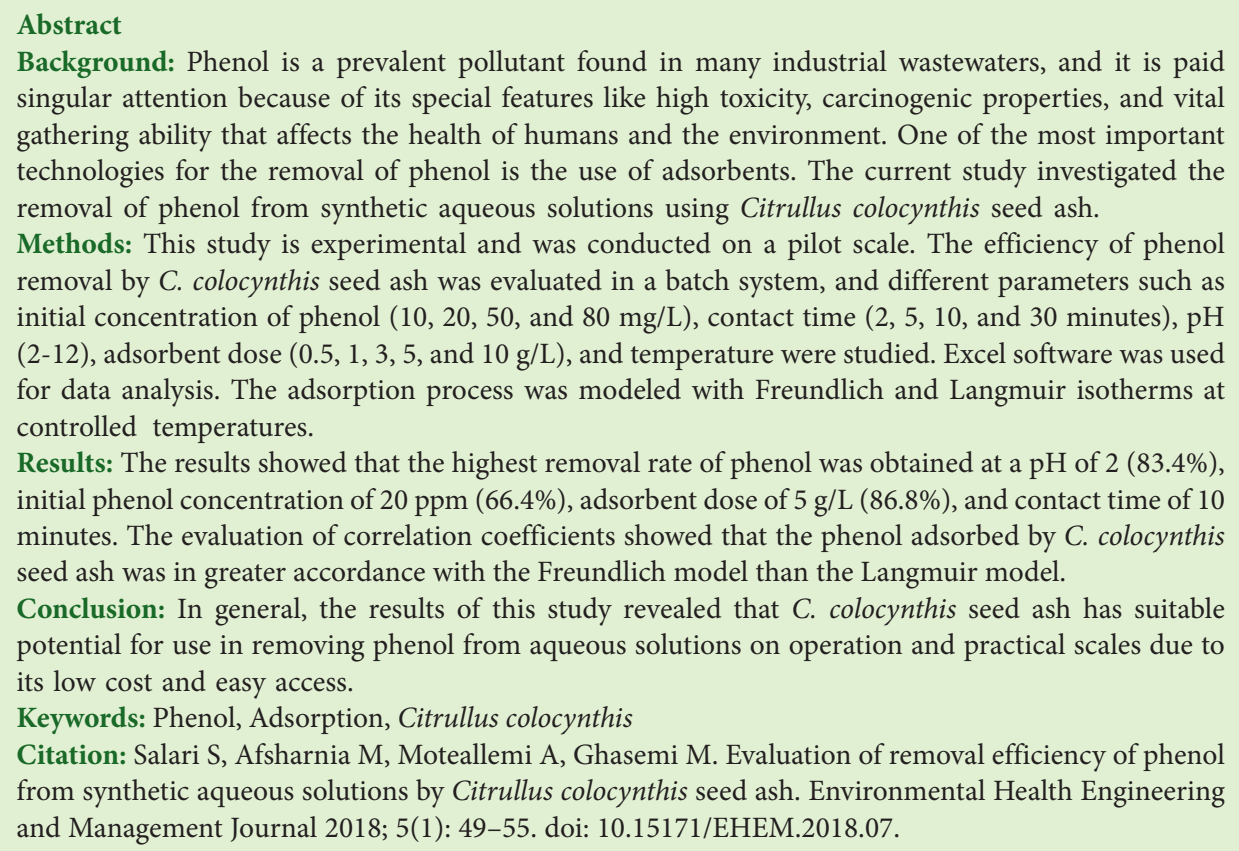

\section{Article History:}

Received: 11 September 2017

Accepted: 20 January 2018

ePublished: 29 January 2018

\section{Introduction}

Phenol is one of the organic water pollutants with the chemical structure $\mathrm{C}_{6} \mathrm{H}_{5} \mathrm{OH}$ that occur because of industrialization (Figure 1) (1). This compound has very high solubility in water and many other organic solvents, and after dissolving in water it creates very little acidity (2). Naturally, phenol is produced from coal tar or gasoline distillation; artificially, it is created through heating sodium benzene sulfate with hydrous soda under high pressure (3). This matter and its derivatives are used in various industries such as resin and plastics, colors, pesticides, pharmaceuticals, oil refineries, and the steel, aluminum, lead, washes, synthetic textiles, and leather industries (4). Phenol is a major pollutant of industrial wastewater. Its compounds produce complexes with tangible tastes and odors in the presence of chlorine (5). The symptoms of acute phenol poisoning include xerostomia, darkening of the color of urine, and the destruction of organs and muscles. Long-term exposure to phenol vapors can cause anorexia, weakness, headache, muscle pain, and jaundice $(6,7)$. Due to the high absorption of phenol through the skin of the hand or forehead (60\%-90\%), in high concentrations, it can lead to death $(8,9)$. Diagnosis, determination, and measurement of phenol compounds in water resources and monitoring their environmental effects play key roles in the control and impact reduction of these combinations (10). According to the standard guidelines of Iran, the maximum allowed concentration of phenol compounds in superficial water, agriculture, and irrigation is $1 \mathrm{mg} / \mathrm{L}$ (11). The World Health Organization (WHO) considers the maximum allowable concentration of phenol in drinking water to be $0.002 \mathrm{mg} / \mathrm{L}$ (12). Also, according to the United States Environmental Protection Agency (USEPA), the permissible concentrations of 


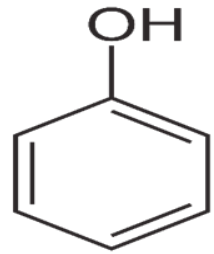

Figure 1. Chemical structure of phenol.

phenol in drinking water and industry effluent are less than $1 \mathrm{mg} / \mathrm{L}$ and $500 \mu \mathrm{g} / \mathrm{L}$, respectively (13). Proper treatment based on existing standards must be carried out so as to reduce the harmful environmental effects of phenol combinations. To date, different methods have been used to treat phenol compounds, such as chemical oxidation, photochemical destruction, precipitation, ion exchange, wet oxidation, electrochemical methods, radiation, membranous filtration, enzymatic filtration, adsorption, and photocatalistic destruction $(3,14)$. Most of these methods have disadvantages like high treatment costs, needs for additive treatment, production of hazardous by-products, high energy consumption, and low efficiency. Among different treatment methods, the adsorption process is one of the simplest and most effective methods for removing poisonous pollutants from aqueous environments (15). In the last two decades, many studies have been carried out on the adsorption of organic compounds with low degradability. In these studies, researchers used produced wastes such as activated carbon (15), coal (16), sugar cane ash (17), agricultural waste (18), and rice bran ash (19) as potential absorbents. In one study, Bazrafshan et al investigated the efficiency of Moringa peregrina tree shell ash as a natural adsorbent for the removal of phenol from aqueous solutions. The effect of important variables such as adsorbent dose, primary phenol concentration, and solution $\mathrm{pH}$ were evaluated. The highest values of removal were obtained at a $\mathrm{pH}$ of 6 , initial concentration of $100 \mathrm{mg} / \mathrm{L}$, and adsorbent dose of $0.4 \mathrm{~g} / \mathrm{L}$. Data experiments were better represented by the Langmuir isotherm than the Freundlich model (20). Citrullus colocynthis is a plant native to southern Iran and Gonabad city in Razavi Khorasan province. This plant has a bitter taste and is most commonly used in Iranian traditional medicine for the treatment of diabetes and the reduction of blood glucose levels. Activating the plant is very easy, and, until now, no comprehensive study has been conducted using Citrullus colocynthis as adsorbent. Thus, the present study applied the seed ash of $C$. colocynthis as an affordable and available adsorbent for the removal of phenol from synthetic aqueous solutions.

\section{Methods}

Preparation of adsorbent

Citrullus colocynthis seeds were collected from the vicinity of Gonabad city, Razavi Khorasan province, Iran. The seeds were separated and washed with distilled water to remove impurities like soluble, colored compounds and sand. Then they were dried in a drying oven $\left(80^{\circ} \mathrm{C}\right)$ and electric furnaces $\left(550^{\circ} \mathrm{C}\right)$ for 4 hours. The ash of the seeds was extracted and sieved through standard sieves of 20 , $30,40,50$, and 100 mesh to obtain particle size (21). The best results were obtained using 20 mesh.

XRD (X-ray Diffraction, D6792-PHILIPS) was used to determine the adsorbent crystalline phases (Figure 2).

\section{Batch adsorption experiments}

Synthetic solution was made by a stock solution containing phenol. Experimental solutions containing the desired concentrations of phenol were prepared by diluting the stock solution $(50 \mathrm{~mL})$. Then, a known mass of $C$. colocynthis seed ash (adsorbent dose) was added to the solution. Batch adsorption experiments were performed in a mechanical shaker to agitate the solutions. Finally, using Whatman grade 42 filter paper, the solutions were filtered and the phenol concentrations were analyzed (22). The amount of phenol adsorbed was calculated using the following formula:

$q_{e}=\frac{\left(C_{0}-C_{e}\right) V}{M}$

where $\mathrm{C}_{0}$ is the initial phenol concentration and $\mathrm{C}_{e}$ is the secondary concentration after reaching the balance, $\mathrm{V}$ is the volume of the solution (L), and $\mathrm{M}$ is the used amount of absorbent ( $\mathrm{g})$.

Method of measuring phenol concentration

The residual phenol concentration was measured using spectrophotometry at a wavelength of $500 \mathrm{~nm}$ in accordance with the standard guidelines for water and wastewater (23).

Effect of initial phenol concentration, $\mathrm{pH}$, adsorbent dose, and contact time

In this study, the effects of different variables such as $\mathrm{pH}$, adsorbent dosage, and initial phenol concentration were investigated $(10,16,19,22)$. In the first stage, the initial $\mathrm{pH}$ of samples in the range of 2-12 was examined. In this stage, the adsorbent dose, initial phenol concentration, and contact time were $3 \mathrm{~g} / \mathrm{L}, 50 \mathrm{mg} / \mathrm{L}$, and 60 minutes,

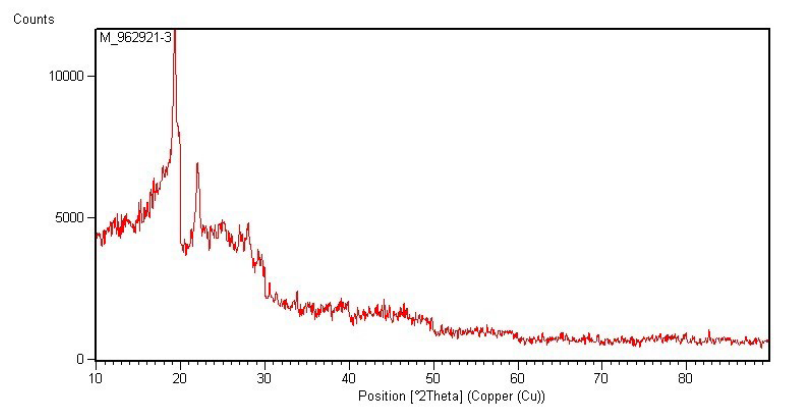

Figure 2. Characteristics of Citrullus colocynthis seed: XRD pattern. 
respectively. After determining the optimal $\mathrm{pH}$, the effects of adsorbent dose at concentrations of $0.5,1,3,5$, and 10 $\mathrm{mg} / \mathrm{L}$, phenol concentration of $50 \mathrm{mg} / \mathrm{L}$, and contact time of 60 minutes were tested. Then, the effects of initial phenol concentrations $(10,20,50,80$, and $100 \mathrm{mg} / \mathrm{L})$ at different times $(2,5,10,30$, and 60 minutes) were examined. The rate of phenol elimination was obtained as a percentage:

$\%=\frac{C_{0}-C_{f}}{C_{0}} .100$

where $\mathrm{C}_{0}(\mathrm{mg} / \mathrm{L})$ is the initial concentration of phenol and $\mathrm{C}_{\mathrm{f}}(\mathrm{mg} / \mathrm{L}$ ) is the final concentration of phenol (after adsorption). All experimental tests were done based on the primary pilot, and all tests were repeated 2 times; the number of analyzed samples was 200 .

\section{Adsorption isotherms}

Adsorption isotherms describe the interactive behavior between an adsorbent and the absorbent. Isotherms are important to optimizing the use of adsorbents and showing the relationship between the phenol concentration of the soluble and the phenol absorption rate by the solid phase, when the two phases are in balance. For this, the Langmuir and Freundlich adsorption models were used to analyze the experimental equilibrium data for the adsorption of phenol by C. colocynthis seed ash. To evaluate data significant to the Langmuir and Freundlich isotherms, the regression coefficient (R2) was used.

The Langmuir isotherm

The Langmuir isotherm is valid for a homogeneous system in which all sorption sites are identical. It is determined using the following formula (24):

$$
\frac{C_{e}}{q_{e}}=\frac{1}{Q_{m} \cdot b}+\frac{1}{Q_{m}} C_{e}
$$

where $\mathrm{C}_{\mathrm{e}}$ is the equilibrium concentration of the solution $(\mathrm{mg} / \mathrm{L}), \mathrm{q}_{\mathrm{e}}$ is the value of adsorbate adsorbed per unit mass of adsorbent $(\mathrm{mg} / \mathrm{g}), \mathrm{b}(\mathrm{L} / \mathrm{mg})$ is the Langmuir adsorption constant, and $\mathrm{Q}_{\mathrm{m}}(\mathrm{mg} / \mathrm{g})$ is the maximum amount adsorbed.

The Freundlich isotherm

This isotherm describes reversible adsorption in a heterogeneous system (24) and is calculated by the following formula:

$$
\log q_{e}=\log K_{f}+\frac{1}{n} \log C_{e}
$$

where $\mathrm{K}_{\mathrm{f}}$ and $\mathrm{n}$ are Freundlich constants, $\mathrm{K}_{\mathrm{f}}((\mathrm{mg} / \mathrm{g})(\mathrm{L} /$ $\left.\mathrm{mg})^{1 / \mathrm{n}}\right)$ is the adsorption capacity of the adsorbent, and $\mathrm{n}$ shows how favorable the adsorption process is. The values of $1 / \mathrm{n}<1$ indicate a normal Friedrich isotherm and cooperative adsorption.
Results

Chemical constituents of Citrullus colocynthis

The presence of the following compounds has been proven in C. colocynthis seeds by phytochemical analysis: proteins $=13.99 \pm 0.06 \%$, crude fibers $=46.73 \pm 0.15 \%$, moisture $=6.43 \pm 0.15 \%$, $a$-tocopherol $=1.90 \pm 0.020$ $\mathrm{g} / 100 \mathrm{~g}$, and fixed oil $=17 \%-28.5 \%$ with a high proportion of unsaturated fatty acids (79.80\%), mainly linoleic acid, oleic acid, a low percentage of saturated, total saturated $20.20 \%$, and a very low level of n-3 poly-unsaturated FA $(0.5 \%)$. The seed oil of Citrullus colocynthis has the following properties: iodine value $=114.46 \mathrm{~g} \mathrm{I} 2 / 100 \mathrm{~g}$, density at $15^{\circ} \mathrm{C}=905.3: \mathrm{kg} / \mathrm{m}^{3}$, kinematic viscosity at $40^{\circ} \mathrm{C}=31.52 \mathrm{~mm}^{2} / \mathrm{s}$, saponification value $=204.44 \mathrm{mg}$ $\mathrm{KOH} / \mathrm{g}$, acid value $=0.98 \mathrm{mg} \mathrm{KOH} / \mathrm{g}$, free fatty acid $=$ $0.49 \%$, caloric value $=39.37 \mathrm{MJ} / \mathrm{kg}$, color $=5 \mathrm{Y}+0.4 \mathrm{R}$, and average molecular weight $=874 \mathrm{~g}$ (25).

The mineral contents of fermented and unfermented Citrullus colocynthis include: Ca $0.250 \pm 0.04, \mathrm{Mg} 0.139 \pm$ $0.041, \mathrm{~K} 0.244 \pm 0.04, \mathrm{Na} 0.36 \pm 0.02, \mathrm{P} 0.176 \pm 0.022 \mathrm{mg} /$ $\mathrm{kg}$; and $\mathrm{Ca} 0.341 \pm 0.18, \mathrm{Mg} 0.167 \pm 0.12, \mathrm{~K} 0.327 \pm 0.10$, $\mathrm{Na} 0.034 \pm 0.16$ and $\mathrm{P} 0.097 \pm 0.14 \mathrm{mg} / \mathrm{kg}$, respectively (26).

\section{Effect of $\mathrm{pH}$}

Solution $\mathrm{pH}$ is one of the most important parameters affecting the chemical properties of both absorbing and adsorbing. In this study, $\mathrm{pH}$ in the range of 2-12 was used. As presented in Figure 3, the removal efficiency was decreased when the $\mathrm{pH}$ value was increased. This result can be explained by the increase in $\mathrm{OH}$ ions and their competitive effect with the phenol anion. As seen in Figure 3, the highest and lowest removal rates were observed in the $\mathrm{pH}$ values of $2(83.4 \%)$ and $12(66.4 \%)$, respectively (Figure 3).

\section{Effect of adsorbent dose on removal efficiency}

To determine the effect of adsorbent dosage on the removal efficiency of phenol, adsorbent doses of $0.5,1,3$, 5 , and $10 \mathrm{~g} / \mathrm{L}$, initial phenol concentration of $50 \mathrm{mg} / \mathrm{L}, \mathrm{pH}$ : 2 , and 60 minutes contact time were considered. As shown in Figure 4, the phenol adsorption rate increased with

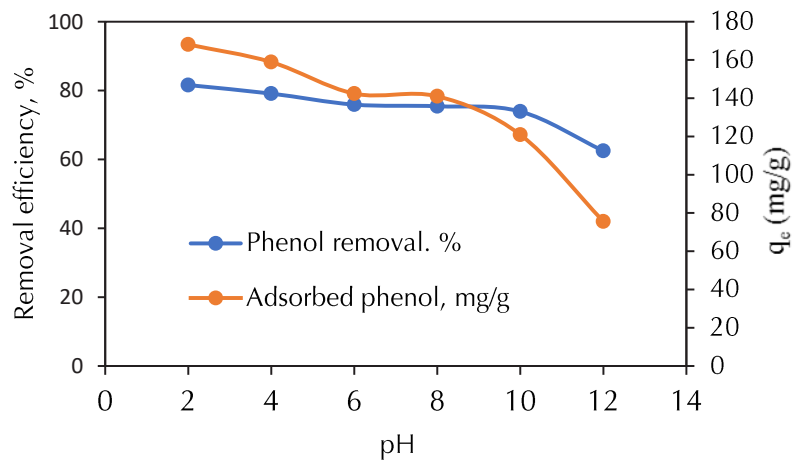

Figure 3. Effects of $\mathrm{pH}$ on phenol removal efficiency (pheno concentration $50 \mathrm{mg} / \mathrm{L}$, adsorbent dose $3 \mathrm{~g} / \mathrm{L}$, contact time $60 \mathrm{~min}$ ). 


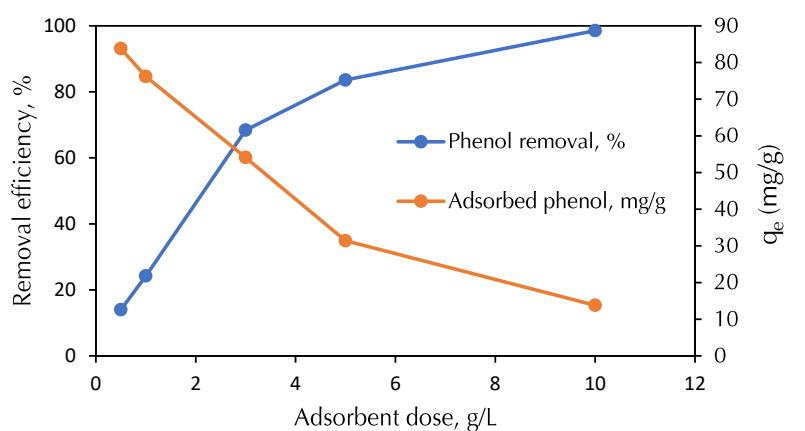

Figure 4. Effects of adsorbent dose on adsorption of phenol by Citrullus colocynthis seed ash (phenol concentration $50 \mathrm{mg} / \mathrm{L}, \mathrm{pH} 2$, contact time $60 \mathrm{~min}$ ).

phenol concentration because of the increased number of sorption sites. Thus, the removal of phenol depends on its concentration.

Effects of initial phenol concentration on efficiency of adsorption process

The effects of primary phenol concentration $(10,20$, 50,80 , and $100 \mathrm{mg} / \mathrm{L}$ ) at contact times of $2,5,10,30$, and 60 minutes and an adsorbent dose of $3 \mathrm{~g} / \mathrm{L}$ were evaluated. Figure 5 shows that by increasing the initial phenol concentration, the phenol removal efficiency was decreased. According to Figure 6, the highest removal efficiency of phenol was obtained in the first 10 minutes

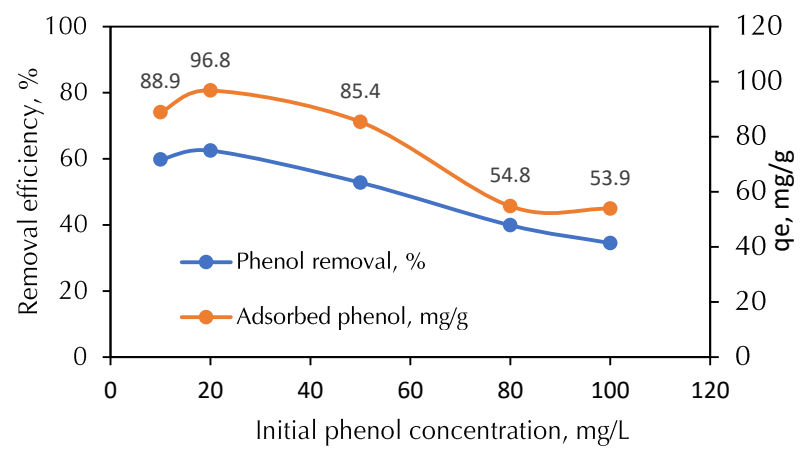

Figure 5. Effects of initial phenol concentration on adsorption process by Citrullus colocynthis seed ash (adsorbent dose of $3 \mathrm{~g} / \mathrm{L}, \mathrm{pH} 2$ ).

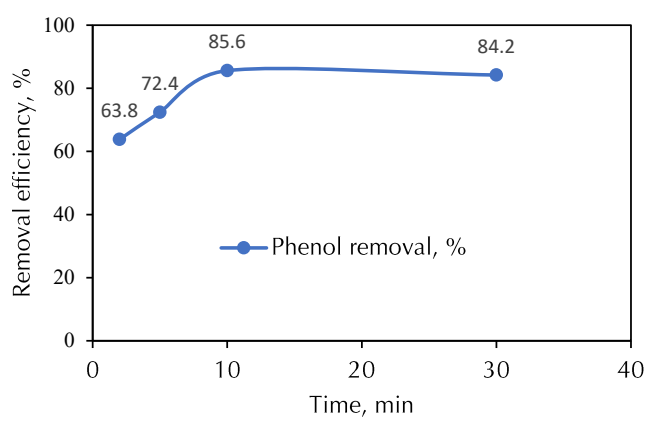

Figure 6. Effect of contact time on adsorption process by Citrullus colocynthis seed ash (Phenol concentration of $20 \mathrm{ppm}$, adsorbent dose of $5 \mathrm{~g} / \mathrm{L}, \mathrm{pH} 2)$. of the test (Figure 6), and the removal efficiency remained almost constant as it reached equilibrium values.

\section{Langmuir and Freundlich isotherms}

A regression coefficient (R2) higher than 0.9 was obtained for both models. The results showed that the Freundlich model is more appropriate for concluding the balanced adsorption of phenol on the adsorbent than the Langmuir model (Figures 7 and 8). Obtained isotherm parameters for phenol adsorption are presented in Table 1.

\section{X-ray diffraction results}

One of the most powerful techniques for characterizing crystalline materials is X-ray diffraction (XRD). XRD provides information on crystal structure and texture, phase, mean grain size, crystallinity, strain, and crystal defects (27). The constructive interference of a monochromatic beam of X-rays that diffract at specific angles from each set of lattice planes produce XRD peaks. The distribution of atoms within the lattice determines the peaks' intensities. As seen in Figure 2, the two broad diffraction peaks observed at around $18^{\circ}$ and $22^{\circ}$ vividly show that the adsorption process made little change in the surface structure of the adsorbent (27) and included compounds such as $\mathrm{C}_{18} \mathrm{H}_{42} \mathrm{CL}_{3} \mathrm{~N}_{6} \mathrm{O}_{2}$ and $\mathrm{C}_{18} \mathrm{H}_{42} \mathrm{CL}_{3} \mathrm{LAN}_{6} \mathrm{O}_{21}$.

\section{Discussion}

Effects of $\mathrm{pH}$

The $\mathrm{pH}$ of a solution is one of the most important and

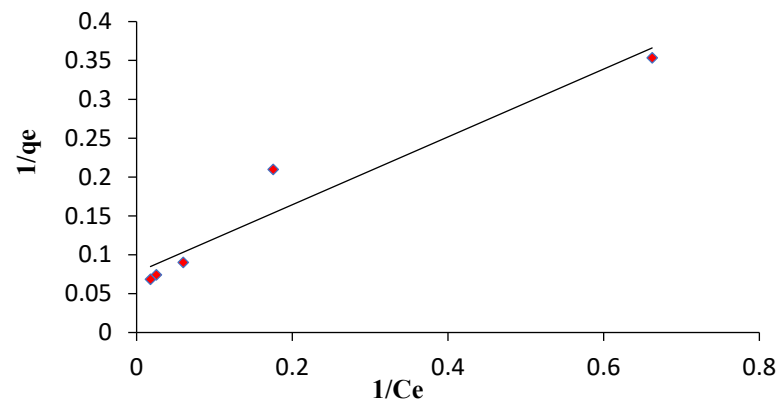

Figure 7. Appropriateness of the Langmuir model to phenol adsorption $\left(R^{2}=0.9348\right)$.

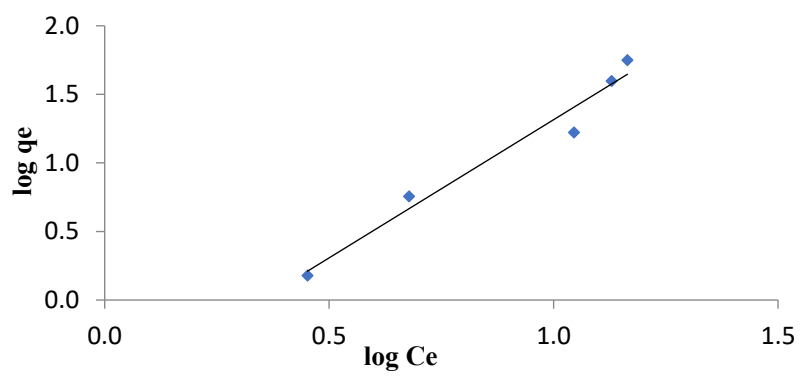

Figure 8. Appropriateness of the Freundlich model to phenol adsorption $\left(R^{2}=0.9674\right)$. 
Table 1. Obtained isotherm parameters for phenol adsorption

\begin{tabular}{llllll}
\hline Langmuir isotherm & \multicolumn{5}{l}{ Freundlich isotherm } \\
\hline $\mathbf{q}_{\mathbf{m}}\left(\mathbf{m g ~ g}^{-1}\right)$ & $\mathbf{K}_{\mathbf{L}}\left(\mathbf{L ~ m g}^{-1}\right)$ & $\mathbf{R}^{2}$ & $\mathbf{k}_{\mathrm{f}}$ & $\mathbf{n}$ & $\mathbf{R}^{\mathbf{2}}$ \\
\hline 13.33 & 0.092 & 0.9348 & 1.75 & 1.51 & 0.9674 \\
\hline
\end{tabular}

effective parameters of the adsorption process, because it affects the electrical charge on the adsorbent surface and the ionization degree of the adsorbate (28). According to Figure 3, the removal efficiency of phenol decreased when $\mathrm{pH}$ was increased. The highest and lowest removal efficiency rates were $83.4 \%$ in $\mathrm{pH}=2$ and $64.1 \%$ in $\mathrm{pH}=$ 12 , respectively. These results can be due to the increase in $\mathrm{OH}$ ions and their competitive effects with phenol anion. The ion section of phenol is calculated by the following formula:

$$
\text { pions }=\frac{1}{\left[1+10^{(P K a-P H)}\right]}
$$

According to the formula above, $\varphi_{\text {ions }}$ is increased by increasing $\mathrm{pH}$. Phenol is a weak acid with $\mathrm{PKa}=10$ that is greatly ionized in solutions. These ions are negatively charged, and because the adsorbent surface is positively charged in low values of $\mathrm{pH}$, a strong attraction is created between the positive and negative ions (29). Senturk et al studied the removal rate of phenol from aqueous solutions by adsorption onto organomodified Tirebolu bentonite (30). Their results revealed that phenol adsorption was constant in $\mathrm{pH}$ values of 3-9, but decreased suddenly in a $\mathrm{pH}$ higher than 9. Similar results were presented for the adsorption of phenol by means of activated carbon, bentonite, and bagasse fly ash, by Halhouli et al (31), Banat et al. (32), and Srivastava et al, respectively (33).

\section{Effects of adsorbent dose}

According to Figure 4, the removal efficiency was increased when adsorbent dose was increased because of the increase in adsorbent surface area and the availability of more adsorption sites (31). The optimal elimination rate of phenol was $86.8 \%(5 \mathrm{~g} / \mathrm{L})$. By increasing the amount of adsorbent to more than $5 \mathrm{~g} / \mathrm{L}$, phenol desorption occurred in the solution. The low adsorption rate can be explained by the lack of phenol concentration in high values of adsorbent (from 5-10 g/L). Similar results were achieved by Cengiz and Cavas (34) and SenthilKumar et al (35). However, these findings differed from the results of a study by Rahmani et al., which showed that by increasing the adsorbent dose from $0.25 \mathrm{~g}$ to $1 \mathrm{~g}$, the residual phenol values were decreased from $40 \mathrm{mg} / \mathrm{L}$ to $1 \mathrm{mg} / \mathrm{L}$. Moreover, the results showed that the amount of adsorbed contaminant per mass unit was decreased by increasing adsorbent values. In accordance with these results, the suitable dose of adsorbent was determined to be $0.5 \mathrm{~g}(36)$.

Effects of contact time and primary phenol concentration The results of this study showed that the efficiency of phenol removal was increased by increasing contact time in the first 10 minutes of the test (Figure 6). The increase in the rate of phenol removal was probably due to the limited empty spaces of adsorbent in high phenol concentrations. Also, these results showed that phenol adsorption is a fast process, because the highest amount of the considered concentrations of phenol was absorbed in the first 10 minutes of the test. The results of a study conducted by Dehghani et al to evaluate the efficiency of multiwalled carbon nanotubes in the removal of phenol from aqueous solutions revealed that phenol removal was increased when contact time was increased. The current study results differed with these in that Dehghani obtained maximum adsorption in the first 30 minutes of the test (37). The cause of this event is the existence of many available empty sites for adsorption at first; with the passage of time, the occupation of the remained sites becomes difficult because of the repulsive force between the solute molecules between the solid phase and the solution (38). In another study conducted by Liao et al on the adsorption of chlorothenols by multiwalled carbon, an equilibrium time of 30 minutes was obtained (39).

As seen in Figure 5, the effect of initial phenol concentration on the adsorption process showed that by increasing phenol concentration, removal efficiency was decreased. The highest and lowest phenol removal rates were obtained in concentrations of $20 \mathrm{ppm}$ (66.4\%) and 100 ppm (33.2\%), respectively, because the initial phenol concentration acts as a driving force, and the resistance of solution mass transfer increases in the adsorbent surrounding the liquid layer and adsorbent surface. Also, increasing phenol concentration decreased the ratio of available surface to the number of adsorbed moles, and that led to a reduction in removal efficiency and an increase in residual phenol in the solution. Senturk et al reported similar results (30).

Phenol adsorption isotherm (Langmuir and Freundlich) Several different models are used to describe adsorption. One of the most important models is adsorption isotherms. In this study, the Langmuir and Freundlich models were used to describe the relationship between the amount of adsorbed phenol and its equilibrium concentration in the solution (40). Adsorption isotherm studies were conducted under optimized conditions $(\mathrm{pH}=2$, adsorbent dosage $=5 \mathrm{~g} / \mathrm{L}$ ), phenol concentrations ranging from 10 to $80 \mathrm{mg} / \mathrm{L}$, and a contact time of 10 minutes. The investigation of correlation coefficients showed that the obtained regression coefficient was higher than 0.9 for both models, and the phenol adsorption by C. colocynthis 
seed ash showed more suitability with the Freundlich model than the Langmuir model (Figures 7 and 8). Similar findings were reported by Feng et al. Equilibrium data was in greater accordance with the Freundlich model than the Langmuir model (41). This finding was also reported in the literature for phenol removal by other adsorbents $(42,43)$.

\section{Conclusion}

In the current study, it was observed that Citrullus colocynthis seed ash can be used effectively for the removal of phenol from aqueous solutions. Among all parameters, $\mathrm{pH}$ had an important role in the adsorption process by this adsorbent. Phenol adsorption was greater in low $\mathrm{pH}$ values than in high values of $\mathrm{pH}$. The results further revealed that the removal efficiency of phenol was increased by increasing adsorbent dose, contact time, and temperature. The evaluation of correlation coefficients showed that phenol adsorption by Citrullus colocynthis seed ash was in greater accordance with the Freundlich model than the Langmuir model. Thus, C. colocynthis seed ash has suitable potential for use in the removal of phenol on operation and practical scales due to its low cost and easy access.

\section{Acknowledgments}

The authors express their gratitude to the Gonabad University of Medical Sciences for the financial support of this project (Project number: 95/79).

\section{Ethical issues}

The authors hereby certify that all data collected during the study is as stated in this manuscript, and no data from the study has been or will be published elsewhere separately.

\section{Competing interests}

The authors declare that they have no competing interests.

\section{Authors' contributions}

All authors contributed equally and were involved in the study design, data collection, and article approval.

\section{References}

1. Razeghi N, Hashemi SH, Jadidi KH, Aghapoor K. Performance of Mesopore MCM-41 with a Nanoporous Structure in Removing Phenol from Water. Journal of Water and Wastewater 2015; 25(6): 2-9. [In Persian].

2. Saeedi M, Pajooheshfar SP. Investigation of phenol adsorption from contained water by activated carbon and carbon of almonds and walnut skin. Quarterly Journal of Environmental Science and Technology 2008; 10(4): 21831. [In Persian].

3. Afsharnia M, Saeidi M, Zarei A, Narooie MR, Biglari H. Phenol removal from aqueous environment by adsorption onto pomegranate peel carbon. Electro physic 2016; 8(11): 3248-56.
4. Nakamoto S, Machida N. Phenol removal from aqueous solutions by peroxidase-catalyzed reaction using additives. Water Res 1992; 26(1): 49-54. doi: 10.1016/00431354(92)90110-P.

5. Caetano M, Valderrama C, Farran A, Cortina JL. Phenol removal from aqueous solution by adsorption and ion exchange mechanisms onto polymeric resins. J Colloid Interface Sci 2009; 338(2): 402-9. doi: 10.1016/j. jcis.2009.06.062.

6. Tor A, Cengeloglu Y, Aydin ME, Ersoz M. Removal of phenol from aqueous phase by using neutralized red mud. J Colloid Interface Sci 2006; 300(2): 498-503. doi: 10.1016/j. jcis.2006.04.054.

7. Brown VK, Box VL, Simpson BJ. Decontamination procedures for skin exposed to phenolic substances. Arch Environ Health 1975; 30(1): 1-6. doi: $10.1080 / 00039896.1975 .10666623$.

8. Baker EL, Landrigan PJ, Bertozzi PE, Field PH, Basteyns BJ, Skinner HG. Phenol poisoning due to contaminated drinking water. Arch Environ Health 1978; 33(2): 89-94. doi: 10.1080/00039896.1978.10667314.

9. Babich H, Davis DL. Phenol: a review of environmental and health risks. Regul Toxicol Pharmacol 1981; 1(1): 90-109. doi: 10.1016/0273-2300(81)90071-4.

10. Maleki A, Mahvi H. Application of agricultural waste products for removal of phenol in aqueous systems. Medical Journal of Hormozgan University 2007; 10(4); 3939. [In Persian].

11. World Health Organization. Guidelines for DrinkingWater Quality. Geneva: WHO; 2004.

12. Roostaei N, Tezel FH. Removal of phenol from aqueous solutions by adsorption. J Environ Manage 2004; 70(2): 157-64. doi: 10.1016/j.jenvman.2003.11.004.

13. Wu C, Liu X, Wei D, Fan J, Wang L. Photosonochemical degradation of phenol in water. Water Res 2001; 35(16): 3927-33. doi: 10.1016/S0043-1354(01)00133-6.

14. Mukherjee S, Kumar S, Misra AK, Fan M. Removal of phenols from water environment by activated carbon, bagasse ash and wood charcoal. Chem Eng J 2007; 129(13): 133-42. doi: 10.1016/j.cej.2006.10.030.

15. Potgieter JH, Bada SO, Potgieter-Vermaak SS. Adsorptive removal of various phenols from water by South African coal fly ash. Water Sa 2009; 35(1): 89-96.

16. Malakootian M, Mesdaghinia A, Rezaei S. Efficiency of ortho-chlorophenol removal from aqueous solutions using activated Fly Ash of Zarand Fossil Fuel Power Plant. Scientific Journal of School of Public Health and Institute of Public Health Research 2014; 12(2): 81-92. [In Persian].

17. Daifullah AA, Girgis BS. Removal of some substituted phenols by activated carbon obtained from agricultural waste. Water Res 1998; 32(4): 1169-77. doi: 10.1016/S00431354(97)00310-2.

18. Gholizadeh A, Kermani M, Gholami M, Farzadkia M, Yaghmaeian K. Removal efficiency, adsorption kinetics and isotherms of phenolic compounds from aqueous solution using rice bran ash. Asian J Chem 2013; 25(7): 3871-3878.

19. Manshouri M, Daraei H, Yazdanbakhsh AR. The feasibility study of ostrich feathers in removing phenol from aqueous solution. J Kermanshah Univ Med Sci 2012; 16(5): 359-66.

20. Bazrafshan E, Kordmostafapour F, Faridi H, Barikbin B. Application of Moringa Peregrina seed extract as a natural coagulant for Phenol removal from aqueous solution. Journal of Birjand University of Medical Sciences 2013; 
19(4): 389-98. [In Persian].

21. Bazrafshan E, Biglari H, Mahvi A. Performance evaluation of electrocoagulation process for phenol removal from aqueous solutions. Fresenius Environmental Bulletin 2012; 21(2): 364-71.

22. Zarei A, Bazrafshan E, Faridi H, Khaksefidi R, Alizadeh $M$. The evaluation of removal efficiency of phenol from aqueous solutions using Moringa peregrina tree shell ash. Iranian Journal of Health Sciences 2013; 1(1): 65-74. doi: 10.18869/acadpub.jhs.1.1.65.

23. American Public Health Association (APHA). Standard Methods for examination of water and wastewater. Washington: American Public Health Association; 2012

24. Mall ID, Srivastava VC, Agarwal NK, Mishra IM. Adsorptive removal of malachite green dye from aqueous solution by bagasse fly ash and activated carbon-kinetic study and equilibrium isotherm analyses. Colloids Surf A Physicochem Eng Asp 2005; 264(1-3): 17-28. doi: 10.1016/j. colsurfa.2005.03.027.

25. Dyanati R, Yousefi Z, Yazdani Cherati J, Balarak D. Investigating phenol absorption from aqueous solution by dried azolla. Journal of Mazandaran University of Medical Sciences 2013; 22(2): 13-20. [In Persian].

26. Nath K, Panchani S, Bhakhar MS, Chatrola S. Preparation of activated carbon from dried pods of Prosopis cineraria with zinc chloride activation for the removal of phenol. Environ Sci Pollut Res Int 2013; 20(6): 4030-45. doi: 10.1007/s11356-012-1325-y.

27. Shrestha S. Chemical, structural and elemental characterization of biosorbents using FE-SEM, SEMEDX, XRD/XRPD and ATR-FTIR Techniques. J Chem Eng Process Technol 2016; 7(3):2-11. doi: 10.4172/21577048.1000295 .

28. Giwa S, Abdullah LC, Adam NM. Investigating "Egusi" (Citrullus Colocynthis L.) seed oil as potential biodiesel feedstock. Energies 2010; 3(4): 607-18. doi: 10.3390/ en3040607.

29. Al-Snafi AE. Chemical constituents and pharmacological effects of Citrullus colocynthis - A review. IOSR J Pharm 2016; 6(3): 57-67.

30. Senturk HB, Ozdes D, Gundogdu A, Duran C, Soylak M. Removal of phenol from aqueous solutions by adsorption onto organomodified Tirebolu bentonite: equilibrium, kinetic and thermodynamic study. J Hazard Mater 2009; 172(1): 353-62. doi: 10.1016/j.jhazmat.2009.07.019.

31. Halhouli KA, Darwish NA, Al-Dhoon NM. Effects of $\mathrm{pH}$ and inorganic salts on the adsorption of phenol from aqueous systems on activated decolorizing charcoal. Sep Sci Technol 1995; 30(17): 3313-24. doi: 10.1080/01496399508013147.

32. Banat FA, Al-Bashir B, Al-Asheh S, Hayajneh O. Adsorption of phenol by bentonite. Environ Pollut 2000; 107(3): 391-8. doi: 10.1016/S0269-7491(99)00173-6.

33. Srivastava VC, Swamy MM, Mall ID, Prasad B, Mishra IM. Adsorptive removal of phenol by bagasse fly ash and activated carbon: equilibrium, kinetics and thermodynamics. Colloids Surf A Physicochem Eng Asp 2006; 272(1-2): 89-104. doi: 10.1016/j.colsurfa.2005.07.016.

34. Cengiz S, Cavas L. Removal of methylene blue by invasive marine seaweed: Caulerpa racemosa var. cylindracea. Bioresour Technol 2008; 99(7): 2357-63. doi: 10.1016/j. biortech.2007.05.011.

35. SenthilKumar P, Ramalingam S, Sathyaselvabala V, Dinesh Kirupha S, Sivanesan S. Removal of copper (II) ions from aqueous solution by adsorption using cashew nut shell. Desalination 2011; 266(1-3): 63-71. doi: 10.1016/j. desal.2010.08.003.

36. Rahmani A, Asgari G, Barjasteh Asgari F, Hedayati Kamran E, Alijani F. Investigation of phenol removal from aqueous solutions using copper-impregnated pumice. Avicenna Journal of Clinical Medicine 2011; 17(4): 50-6. [In Persian].

37. Dehghani MH, Alimohammadi M, Mahvi AH, Rastkari N, Mostofi M, Gholami M. Performance of multiwall carbon nanotubes for removal phenol from aqueous solutions. Iranian Journal of Health and Environment 2014; 6(4): 491502. [In Persian].

38. Wang L, Zhang J, Zhao R, Zhang C, Li C, Li Y. Adsorption of 2,4-dichlorophenol on Mn-modified activated carbon prepared from Polygonum orientale Linn. Desalination 2011; 266(1-3): 175-81. doi: 10.1016/j.desal.2010.08.022.

39. Liao Q, Sun J, Gao L. Adsorption of chlorophenols by multi-walled carbon nanotubes treated with $\mathrm{HNO} 3$ and NH3. Carbon 2008; 46(3): 553-5. doi: 10.1016/j. carbon.2007.12.009.

40. Gholizadeh A, Kermani M, Gholami M, Farzadkia M. Kinetic and isotherm studies of adsorption and biosorption processes in the removal of phenolic compounds from aqueous solutions: comparative study. J Environ Health Sci Eng 2013; 11(1): 29. doi: 10.1186/2052-336x-11-29.

41. Feng J, Qiao K, Pei L, Lv J, Xie S. Using activated carbon prepared from Typha orientalis Presl to remove phenol from aqueous solutions. Ecol Eng 2015; 84: 209-17. doi: 10.1016/j.ecoleng.2015.09.028.

42. Viswanathan N, Meenakshi S. Enriched fluoride sorption using alumina/chitosan composite. J Hazard Mater 2010; 178(1-3): 226-32. doi: 10.1016/j.jhazmat.2010.01.067.

43. Dou X, Zhang Y, Wang H, Wang T, Wang Y. Performance of granular zirconium-iron oxide in the removal of fluoride from drinking water. Water Res 2011; 45(12): 3571-8. doi: 10.1016/j.watres.2011.04.002. 